\title{
Antipredator behavioural compensation of proactive personality trait in male Eurasian siskins
}

Jordi Pascual*, Joan Carles Senar

Behavioural and Evolutionary Ecology Research Unit (CSIC), Natural History Museum of Barcelona, Barcelona, Spain

Article history:

Received 6 September 2013

Initial acceptance 15 October 2013

Final acceptance 13 January 2014

Available online $x x x$

MS. number: 13-00768R

* Correspondence: J. Pascual, Natural History Museum of Barcelona, Passeig Picasso s/n, 08003 Barcelona, Spain.

E-mail address: jpascualsala@gmail.com (J. Pascual). 
Many animals show behavioural syndromes (i.e. suites of correlated behaviours across multiple situations). These behavioural correlations, however, imply limitations in the behavioural plasticity of individuals when facing the trade-off between predation risk and starvation risk. Some models suggest that proactive animals prioritize the reduction of starvation risk, while reactive animals do the opposite. Therefore, fast explorers that are also bold (i.e. proactive) are assumed to pay a predation cost associated with their behavioural trait. However, it has recently been suggested that proactive individuals may be able to compensate for their higher risk of predation by adopting some antipredator behaviours. In this study we tested these two alternative hypotheses with wild wintering Eurasian siskins, Carduelis spinus, foraging at artificial feeders. Male siskins have a melanin-based black bib that has been found to be correlated with exploratory behaviour, aggressiveness and dominance, and therefore is a signal of proactivity. We found that male siskins with large black bibs uttered more distress calls upon capture and displayed a vigilance strategy that improved predator detection. Moreover, this vigilance strategy did not reduce food intake rate. These results show that proactive individuals are not reckless, but instead compensate for their personality trait with stronger antipredator behaviours, and thus, do not necessarily have to pay a predation cost. Our results support the view of a positive relationship between eumelanism, proactive personality and the display of antipredator behaviours.

Keywords:

antipredator behaviour, distress call, foraging melanism, personality, plumage coloration, plumage signal, vigilance 
Recently, Sih, Bell, and Johnson (2004, p. 372) described a behavioural syndrome as 'a suite of correlated behaviors reflecting between individual consistency in behavior across multiple situations'. In accordance with this definition, some experimental studies and models have found a correlation between boldness and exploratory behaviour (Dammhahn \& Almeling, 2012; Quinn \& Cresswell, 2005; van Oers, Drent, de Goede \& Van Noordwijk, 2004; Wolf, van Doorn, Leimar \& Weissing, 2007) and a correlation between exploratory behaviour, aggressiveness and dominance (David, Auclair \& Cézilly, 2011; Mateos-González \& Senar, 2012; Wolf et al., 2007). A behavioural syndrome, however, also limits the behavioural plasticity of animals confronting changing environmental conditions (Sih, Kats \& Maurer, 2003; Sih et al., 2004). Thus, a fast explorer that is also bold and aggressive (i.e. proactive; Sih et al., 2004) may suffer the consequences of its risk-taking behaviour in high predation risk situations (Jones \& Godin, 2010; Quinn \& Cresswell, 2005; van Oers et al., 2004).

Personality has a strong influence on the way animals face the trade-off between the risk of predation and starvation (e.g. Quinn, Cole, Bates, Payne \& Cresswell, 2011). It has been suggested that proactive animals prioritize the reduction of starvation risk, while reactive animals do the opposite (Biro \& Stamps, 2008). Carter, Goldizen, and Tromp (2010) studying Namibian rock agamas, Agama planiceps, found empirical support for this hypothesis. Accordingly, in a recent review of the effect of life history strategy on fitness, bold individuals had higher productivity but with the handicap of a reduction in survival (Smith \& Blumstein, 2007). In contrast, Jones and Godin (2010, p. 626) recently suggested that proactive individuals might have evolved antipredator behaviours to compensate for the higher risk of predation associated with their behavioural trait ('compensation hypothesis'). In line with this hypothesis, Godin and Dugatkin (1996) found that bold and conspicuous Trinidadian guppies, Poecilia reticulata, maintained greater escape distances from cichlid fish predators, while Carter, Marshall, Heinsohn, and Cowlishaw (2012) found no correlation between responses to a novel object and responses to a threat in wild chacma baboons, Papio ursinus. Couchoux and Cresswell (2012), studying redshanks, Tringa totanus, found no evidence of a behavioural syndrome related to risk management, and the only repeatable trait they found for this species was vigilance, which was adjusted in a flexible way to the riskiness of the situation. All these findings might explain the positive correlation between exploratory behaviour and survival (Smith \& Blumstein, 2007) and the lack of a behavioural syndrome (Réale, Reader, Sol, McDougall \& Dingemanse, 2007, p. 305) reported for some species.

In line with the hypotheses formulated by Jones and Godin (2010), in the present study we tested whether proactive Eurasian siskins, Carduelis spinus, show a behavioural carryover leading to a reduction in antipredator behaviours (Sih et al., 2004) while keeping high food intake rates (Biro \& Stamps, 2008; handicap hypothesis), or whether they evolved antipredator behaviours to compensate for the high risk of predation associated with their personality trait (compensation hypothesis). Siskins are socially foraging birds whose males have a melaninbased black bib that is a reliable signal of status, so that individuals with larger bibs are more dominant (Senar, Camerino, Copete \& Metcalfe, 1993; Senar \& Camerino, 1998). The social system of this species is feudal, so that dominant individuals mainly fight each other and, therefore, are more aggressive than subordinates (Senar \& Domènech, 2011). Moreover, male siskins with large black bibs are more exploratory (Mateos-González \& Senar, 2012). Therefore, 
in this species we can classify males with large black bibs as having a proactive personality trait and males with small black bibs as having a reactive personality trait (Sih et al., 2004).

To test whether proactive or reactive siskins show more antipredator behaviours, we focused on vigilance behaviour, which significantly reduces the probability of capture (Lima \& Dill, 1990), and on distress calls, which significantly increase the probability of escape from predators once captured (Conover, 1994; Laiolo, Tella, Carrete, Serrano \& López, 2004). We also examined reasons for departure from foraging and foraging bout lengths of the siskins. We observed a population of wintering siskins foraging at two feeders that differed in predation risk (high versus low). Short interscan durations are the best strategy to detect predators quickly, both in theoretical models (Hart \& Lendrem 1984) and in experimental studies (Whittingham, Butler, Quinn \& Cresswell, 2004). Moreover, siskins foraging in groups specifically reduce interscan durations with increasing predation risk (Pascual \& Senar 2013). According to the handicap hypothesis, large-bib siskins (proactive) should show (1) longer interscan durations, lower scan rates and/or lower percentages of time scanning, (2) fewer disturbance-related departures and (3) longer foraging bout lengths while feeding, especially at the high predation risk feeder, and (4) utter fewer distress calls once captured. In contrast, according to the compensation hypothesis, we would expect the opposite. In the present study we tested the above predictions and we also analysed food intake rates and aggression rates as well as the proportion of males of each bib size category on the two feeders as relevant variables to understand and interpret the results better.

\section{METHODS}

\section{Model Species and Study Site}

Wintering siskin populations are formed by resident and transient birds (Senar et al., 1992). Residents stay in the area for several weeks, whereas transients normally stay for a few hours or days. The usefulness of the black bib as a signal of status is especially relevant to transients, since residents have previous experience with one another and are dominant over transients (Senar, 2006). Therefore, in the present study we only selected transient birds (i.e. not colour ringed; see below) as focal individuals. The study was carried out in an area of orchards, small pine woods (Pinus halepensis) and gardens in the suburban area of Barcelona city (Catalonia, northeast Spain) from October 1996 to March 1997.

\section{Bird Ringing and Videotaping}

We captured siskins weekly from 19 October 1996 to 15 March 1997 (i.e. the wintering season) and marked them with numbered aluminium rings $(N=584)$. Birds that were recaptured repeatedly (i.e. stayed in the area as 'residents'; Senar et al., 1992) were also given unique colour ring combinations $(\mathrm{N}=104)$, allowing long-distance identification. We placed two identical feeders $(0.08 \mathrm{~m}$ wide, $1 \mathrm{~m}$ long) in the same area where a sparrowhawk, 
Accipiter nisus, routinely hunted, and hence where the siskins faced a real and high risk of predation (Pascual, Senar \& Domènech, 2014). One of the feeders was placed near protective cover (low predation risk feeder, LPF), and the other feeder was placed far from protective cover (high predation risk feeder, HPF). Mean \pm SE group size was $9.10 \pm 0.38$ birds on the LPF and $7.87 \pm 0.44$ birds on the HPF (for more details, see Pascual \& Senar, 2013). The feeders were filled with turnip, Brassica rapa, seeds, and birds foraging on them were simultaneously videotaped from a hide with two video cameras. We filmed only half the length of the feeders when videotaping, since they were too long to be recorded in the same image. Therefore, to prevent any biases and to increase the number of individuals recorded, we shifted the video camera every $2 \mathrm{~min}$ from one half of the feeder to the other half. In total, 27 flocks were recorded at feeders on 10 different days from 14 February to 11 March 1997, between 1000 and 1700 hours. The risk of predation at the area was real and high because we witnessed six attacks of a male sparrowhawk on birds foraging at the experimental feeders, and we found the remains of over 25 siskins caught by a predator in a pine wood within $20 \mathrm{~m}$ of the feeders (Pascual et al., 2014). The experimental design is validated elsewhere (Pascual \& Senar, 2013), and we found that (1) $53 \%$ of the departures of focal siskins from the HPF were sudden departures of all or most of birds foraging at the feeder, usually after an alarm call, compared with $13 \%$ at the LPF, (2) $60 \%$ of the departures from the LPF were related to agonistic interactions, compared with $37 \%$ at the HPF, and (3) the proportion of time that siskins devoted to agonistic interactions was almost three-fold higher at the LPF than at the HPF. Therefore, we can confidently say that the perceived predation risk was much higher at the HPF than at the LPF and that aggression rates were much higher at the LPF than at the HPF. On the other hand, in the same study we found that siskins responded to an increase in predation risk by shortening interscan durations, whereas they responded to an increase in interference competition by lengthening scan durations.

\section{Ethical Note}

We captured siskins using Yunick platform traps, mist nets and clap nets. Yunick traps (Senar, 1988) consist of a platform feeder wrapped in wire mesh with a trap door on each side through which the birds gain access to the feeder. The trap doors are connected to a long rope, which, when pulled (from within a hide), causes the trap doors to fall down vertically and suddenly. Siskins captured in Yunick traps or clap nets were immediately removed and ringed, measured and released. Mist nets were visited every $0.5 \mathrm{~h}$. The manipulation and ringing of siskins was carried out by expert bird ringers under the authorization of the Ornithological Catalan Institute. The capture of birds was carried out under the special authorization for scientific capture 206/97 from the Subdirecció General de Conservació de la Natura from the Departament d'Agricultura, Ramaderia i Pesca of the Generalitat de Catalunya.

\section{Data Obtained from Tapes}


During videorecording we looked for transient siskin males from the hide with binoculars and we visually classified their bib size in 10 categories, from 1 (without bib) to 10 (very large bib). Then, when visualizing the video recordings in the laboratory, we looked for siskins with the bib size identified and we generated two databases from two subsamples, which we call 'random' and 'undisturbed'. For the undisturbed subsample, we only selected birds that foraged on the feeder for more than $30 \mathrm{~s}$ and that fed without fighting or moving for at least $30 \mathrm{~s}$ (for more details and justification, see Pascual \& Senar, 2013). In our undisturbed database, we looked for all pairs of transient siskins that differed by more than two categories of bib size (so that their bib size was rather different) and that had been foraging simultaneously or nearly so (to isolate the effects of bib size from those of flock size, time of day and other time-related variables). We categorized the birds of the pair as large-bib and small-bib individuals. When we found a video record of three transient male siskins differing in bib size and foraging simultaneously, we selected for the pair the two individuals that differed more in bib size. In the very few cases when we found four transient male siskins differing in bib size and foraging simultaneously, we paired the males so that the differences in bib size between males in the two pairs were maximized. We found 26 pairs of siskins at the LPF that differed by a mean \pm SE of $4.9 \pm 0.3$ bib size categories (Wilcoxon matched-pairs test: $Z=4.46, P$ $<0.0001$ ) and 14 pairs of siskins at the HPF that differed by a mean of $4.3 \pm 0.3$ bib size categories (Wilcoxon matched-pairs test: $Z=3.30, P=0.001$ ). Both birds in each pair at the LPF had been foraging simultaneously, and both birds in each pair at the HPF had been foraging on the same day, in the same flock and with a mean difference in time of $0.31 \pm 0.14 \mathrm{~h}$ (maximum $=1.69 \mathrm{~h}$; we only found four pairs foraging simultaneously on this feeder). The vigilance variables estimations were based on this undisturbed subsample. We analysed the behaviour of each bird from $30 \mathrm{~s}$ of video recordings following Pascual and Senar (2013), and we calculated the following variables: percentage of time spent scanning (as the number of frames with the tip of the beak raised to eye level or higher), mean interscan duration (measured in frames), scan rate (as the total number of head-up intervals) and pecking rate (as the total number of pecks, an estimate of food intake rate).

The random subsample, in contrast, was chosen without the restrictions of the undisturbed subsample (i.e. independently of the birds' time on the feeder and of their behaviour while foraging on it). We found 22 pairs of male transient siskins at the LPF and 20 pairs of male transient siskins at the HPF with the bib size identified and differing by more than two bib size categories, and the two birds of the pair were foraging simultaneously. The mean \pm SE difference in bib size between large-bib and small-bib siskins in each pair was $5.05 \pm 0.36$ bib size categories at the LPF (Wilcoxon matched-pairs test: $Z=4.11, P<0.0001$ ) and $6.15 \pm 0.41$ bib size categories at the HPF (Wilcoxon matched-pairs test: $Z=3.92, P<0.0001$ ). We analysed this subsample to estimate the variables that were highly affected by the selection conditions of the undisturbed subsample: time spent on the feeders (i.e. foraging bout length) and percentage of time spent in aggressive interactions.

We think the risk of pseudoreplication in our study was low since (1) we worked only with transient birds, which stay in the area for a few hours or days, and make up approximately three-quarters of the population (Senar et al., 1992), (2) the birds were recorded on 10 different days within a range of 26 days, (3) we selected birds from 27 different flocks and (4) 
flock sizes were large ( $>50$ birds). Therefore, the probability of repeating a bird as a focal individual was extremely low and the probability of repeating a pair was negligible.

In addition, we recorded the presumed reasons for the departure of 47 male transient siskins at the LPF and 39 male transient siskins at the HPF from the random subsample. We classified reasons for departure as 'aggression' if the bird departed upon being attacked, as 'disturbance' if the focal bird and other flock members departed suddenly and quickly (usually after an alarm call was uttered by a conspecific or heterospecific), or as 'individual-based' if the bird's departure was not elicited by aggression or a sudden disturbance. Finally, from all the video recordings made when there were siskins foraging at the LPF and HPF simultaneously (in some periods there were siskins at the LPF and not at the HPF, presumably because of the higher predation risk at the HPF), we noted the bib size category (in 10 categories; see above) of all the male transient siskins with the bib size category identified while filming and watching the siskins with binoculars. In total, the bib size category was identified for 220 male transient siskins at the LPF and 81 male transient siskins at the HPF (more birds were videorecorded at the LPF because this feeder was clearly preferred by the siskins for foraging; see Pascual \& Senar, 2013).

\section{Relationship between Black Bib Area and Distress Calls}

We measured the length ( $\mathrm{L}$, in $\mathrm{mm}$ ) and width $(\mathrm{W}$, in $\mathrm{mm}$ ) of the black bib of 248 transient siskins captured during the winter 1996-1997, and we calculated their black bib area (A, in $\mathrm{mm} 2$ ) as $A=0.594 \times \mathrm{L} \times \mathrm{W}$, following Senar et al. (1998). However, only 13 of the males uttered distress calls once in the hands of the ringers. To increase our sample size, we used data from the winter of 1990-1991, when more siskins visited the study area (144 residents, 1542 transients). In that winter, we measured the black bib area of 476 male transient siskins captured from 20 October 1990 to 7 April 1991, following the same methodology as for the winter of 1996-1997, and of these, 44 uttered distress calls. As a result, our overall sample size included 57 male transient siskins that uttered distress calls and 667 male transient siskins that did not utter distress calls. As in the analysis of vigilance, we only considered data of transient siskins because for them the black bib is more useful, our sample size was larger, and because transients probably perceived the capture as a predation event, whereas residents, which had previously experienced capture and release, could know that they would be released after a while.

\section{Data Analysis and Transformation}

The absolute time on the feeder could not be recorded for 22 out of 60 siskins at the LPF and for 17 out of 46 siskins at the HPF because they disappeared from our view before departing (either because we shifted the video camera, because they changed their location from one half of the feeder to the other, or because the videotape or the battery life of the video camera ended). To compare time spent on the feeder by large-bib and small-bib males, we 
computed survival scores with a survival analysis (using the software program Statistica 8.0, StatSoft, Inc., College Station, TX, U.S.A.), treating incomplete times on the feeder as censored data. We did this instead of using only birds with complete times on the feeder because using complete times would have biased the data towards birds with short values for this variable.

The percentage of time spent in aggressive interactions and the survival scores for time on the feeder did not fit a normal frequency distribution, so we applied type I rank transformation on these variables (Conover \& Iman, 1981) to allow use of parametric statistics. We ranked data from the two feeders and the two categories of bib size together to obtain both betweenfeeder information and between-bib size information (Conover \& Iman, 1981). We did not use other transformations for these variables because the data could not be normalized with them. However, we normalized the percentage of time scanning by cube transformation, the mean interscan duration by reciprocal transformation and pecking rate by logarithm transformation.

We compared vigilance and feeding variables, aggression rates and time on the feeder for large-bib and small-bib siskins with repeated measures ANOVA using Statistica 8.0 (StatSoft, Inc.), taking feeder and bib size and the interaction between them as predictor variables and the two measures for each pair as the dependent variable. However, the interaction could not be tested for the rank-transformed variables because this kind of transformation does not allow tests of interactions (Blair, Sawilowsky \& Higgins, 1987). To compare birds' reasons for departure from the feeders, we grouped male transient siskins into three new categories of bib size: 'small', which included individuals of the former categories 1-4; 'medium', which included individuals of the former categories 5-7; 'large', which included individuals of the former categories 8-10. Then we compared this categorical variable between feeders and between bib sizes with the Pearson chi-square test in Statistica 8.0 (StatSoft, Inc.). Finally, to compare the proportion of the bib size categories between feeders, we also grouped the siskins into the three new categories of bib size, as described above (small, medium, large) and applied a Pearson chi-square test to the observed and expected frequencies for each category.

We compared the black bib area among siskins that did and did not utter distress calls using a Mann-Whitney $U$ test, because the black bib area showed a bimodal distribution and thus did not show a normal frequency distribution (Senar et al., 1993).

\section{RESULTS}

\section{Vigilance and Foraging Variables}

Siskins with large black bibs showed a vigilance system with shorter interscan durations and higher scan rates than siskins with small black bibs (Table 1, Fig. 1). The proportion of the effect explained by bib size was (partial eta-squared) $16 \%$ for interscan duration and $10 \%$ for scan rate. Males of the two bib size categories did not differ in the percentage of time spent 
scanning, pecking rate, time on feeder or percentage of time spent in aggressive interactions (Table 1). Mean interscan durations were shorter at the HPF than at the LPF, mean scan rates were higher at the HPF than at the LPF and survival scores of time on feeder were lower at the HPF than at the LPF (Table 1), but we detected no interaction between bib size and feeder for any of the analysed variables (Table 1). Departure reasons did not differ significantly between bib size categories at the HPF (Pearson chi-square: $\chi 24=3.33, \mathrm{~N}=39, \mathrm{P}=0.50$ ) or the LPF $(\chi 24=4.00, N=47, P=0.41)$. Finally, we found no significant differences in the proportion of bib size categories between feeders (HPF: small $=38 \%$, medium $=28 \%$, large $=33 \%, N=81$; LPF: small $=34 \%$, medium $=34 \%$, large $=32 \%, N=220 ; \chi 22=0.82, P=0.66$ ).

\section{Distress Calls}

Siskins that uttered distress calls had larger black bibs than siskins that did not utter distress calls (Mann-Whitney U test: $U=15733, N 1=57, N 2=667, P=0.031$; Fig. 2).

\section{DISCUSSION}

In this study of wintering siskins we found that a plumage coloration signal (the black bib), which is positively correlated with exploratory behaviour (Mateos-González \& Senar, 2012), aggressiveness (Senar \& Domènech, 2011) and dominance (Senar et al., 1993) and is thus a proactive personality trait (Sih et al., 2004), is also related to antipredator vigilance behaviour. In line with the predictions of the compensation hypothesis, and against the predictions of the handicap hypothesis, we found that large-bib males (i.e. proactive individuals), as compared to small bib males (i.e. reactive individuals), adopted a vigilance strategy with more but shorter feeding sessions (i.e. shorter interscan durations and higher scan rates with an equal percentage of time scanning). This is the same strategy used by siskins when their perceived risk of predation is increasing (Pascual \& Senar, 2013). Shortening of head-down intervals and the related increase in head-up frequencies have been shown to be the best predictors of the time taken to respond to a predator attack (Cresswell, Quinn, Whittingham \& Butler, 2003; Hart \& Lendrem, 1984; Whittingham et al., 2004). Therefore, our results clearly show that siskins with large black bibs adopted a vigilance strategy that allowed them to react sooner to a predator attack, supporting the compensation hypothesis. That differences in the vigilance system of proactive and reactive individuals were found at both feeders, and not only at the HPF, as predicted, suggests that, even when siskins adapted their vigilance behaviour to the predation risk of the foraging patch (i.e. high reduction of interscan durations from LPF to HPF; in line with adaptive vigilance found by Couchoux \& Cresswell, 2012), their personality still influenced the adaptability of their vigilance to the variable conditions (in line with Quinn et al., 2011) or their level of activity.

Siskins with large black bibs increased their vigilance of predators in a way that was not costly in terms of foraging efficiency, as found by Cresswell et al. (2003) for chaffinches, Fringilla coelebs. They did not increase the proportion of time spent scanning or reduce pecking rate or 
foraging bout length relative to males with small black bibs. In addition, despite the feudal social system of siskins (Senar \& Domènech, 2011), males with large black bibs (i.e. dominants) did not spend a greater percentage of time in aggressive interactions than subordinates at either feeder. These findings together suggest that, in siskins, proactive males are good at both foraging and detecting predators (Cresswell et al., 2003). However, we cannot rule out the possibility that the vigilance and foraging strategy of proactive siskins could have some undetected negative effect on total daily feeding, such as a reduction in the number of visits to the feeders (a variable that could not be measured in this study). Nevertheless, given that a previous study (Senar, Polo, Uribe, \& Camerino, 2000) found no correlation between bib size and body mass in male siskins and a positive correlation between both variables after controlling for metabolic rate, it seems unlikely that dominants have a lower daily food intake.

The proportion of males of each bib size category did not differ between the two feeders. In terms of boldness (Réale et al., 2007), males with large bibs should have been more prone to feed on the high predation risk feeder (Carter et al., 2010). But, in terms of dominance, we would expect the opposite (i.e. small-bib subordinates should have been displaced to the riskier foraging patch; e.g. Ekman, 1987; Koivula, Lahti, Rytkönen \& Orell, 1994). However, small-bib male siskins, while subordinate to large-bib males, are dominant to female siskins (Senar \& Domènech, 2011) and dominant to male and female serins, Serinus serinus, foraging with them (J. Pascual, personal observation). Therefore, we did not expect small-bib males in our study to be displaced to the high predation risk feeder. The lack of difference in the proportion of bib size categories at the two feeders might reflect the combined effects of boldness and compensation for predation risk in male transient siskins, giving some additional support to the compensation hypothesis.

Also in line with the predictions of the compensation hypothesis, we found that siskins that uttered distress calls had larger black bibs than siskins that did not utter distress calls. Therefore, proactive siskins not only have a lower probability of being captured by predators, but they also show stronger escape behaviours than reactive siskins, thereby further increasing their probability of survival to predator attacks. A positive relationship between exploratory behaviour and the production of distress calls was also recently found in black-capped chickadees, Poecile atricapillus (Guillette \& Sturdy, 2011).

Our results are opposite to the findings of Jones and Godin (2010) for juvenile convict cichlids, Amatitlania nigrofasciata, where fast explorers were slow reactors to a predator attack. However, our results are in accordance with the findings of Godin and Dugatkin (1996) for Trinidadian guppies. In this species, conspicuous individuals are preferentially attacked by cichlid fish predators, and they compensate for this handicap by having a higher inspection rate of predators and a greater flight initiation distance. Therefore, in this species, a bold personality is associated with lower anxiety in the presence of predators (or risk aversion), which is useful in deterring predator attacks.

The black bib of siskins is a melanin-based coloration (Mateos-González \& Senar, 2012), probably mostly related to eumelanin. It has been suggested that the pleiotropic effects of the genes regulating the synthesis of eumelanin could be the source for an association between melanin-based coloration and behavioural syndromes, with darker eumelanic individuals being 
more aggressive, more sexually active and less sensitive to stressful factors (Ducrest, Keller \& Roulin, 2008). Therefore, melanin-based coloration would be a signal of proactive personality as has been described for the siskin (Mateos-González \& Senar, 2012). Many studies have explored the relationship between melanin-based coloration and antipredator behaviours. Female eumelanic tawny owls, Strix aluco, and buzzards, Buteo buteo (Boerner \& Krüger, 2009; Da Silva et al., 2013) and male eumelanic great tits, Parus major, and house sparrows, Passer domesticus (Reyer, Fischer \& Steck, 1998; Quesada \& Senar, 2007) are more aggressive towards predators near their nest (but male melanic buzzards are less aggressive; Boerner \& Krüger, 2009). Brown marsh harriers, Circus aeruginosus, are more involved in mobbing behaviour than grey individuals (Sternalski \& Bretagnolle, 2010), and eumelanic barn owl, Tyto alba, nestlings hiss more to predators (van den Brink, Dolivo, Falourd, Dreiss \& Roulin, 2012). Hence, in accordance with the compensation hypothesis, the general trend is that proactive individuals show stronger antipredator behaviours, and not the opposite, at least when proactivity is associated with eumelanic coloration.

Of course, in evolutionary terms, if proactivity and reactivity are alternative, coexisting personality traits, both must imply costs as well as benefits. In regard to siskins, MateosGonzález and Senar (2012) discussed this issue, concluding that reactive males would benefit from higher sociability, avoidance of potentially harmful prey and better exploration of their environment, while proactive males would benefit from preferential access to resources. Hence, a higher probability of predation for proactive individuals must not be a necessary condition for maintenance of the two alternative traits. More research will be needed to understand better the costs of proactivity (and eumelanism) concerning the generality of animal taxa.

\section{Conclusions}

In siskins, we found that a plumage coloration signal related to personality (the black bib) was also related to antipredator vigilance behaviour. The proactive trait was not associated with any behavioural carryover in terms of predation cost, but rather was compensated for by a vigilance strategy that improved predator detection and escape behaviour without reducing food intake rate. Our results support recent papers relating eumelanism with aggressiveness and stronger antipredator behaviours. Hence, proactive personality, at least when associated with eumelanism, should not be associated with recklessness or incautiousness, but instead with a higher response to predators.

\section{Acknowledgments}

This work was supported by the Spanish Ministry of Science and Innovation (Research Projects BOS 2000-0141 and CGL 2009-10652). We thank David Boné, Anna Serra, Esther Vilamajó and Miquel Boix for field assistance and Nuria Mallén and M. Luisa Arroyo for laboratory 
assistance. We also thank Jordi Domènech for his methodological advice, the anonymous referees for their critical discussions and Kris Bruner for improving the English.

\section{References}

Biro, P. A., \& Stamps, J. A. (2008). Are animal personality traits linked to life-history productivity? Trends in Ecology \& Evolution, 23, 361-368.

Blair, R. C., Sawilowsky, S. S., \& Higgins, J. J. (1987). Limitations of the rank transform statistic in tests for interactions. Communications in Statistics - Simulation and Computation, 16, 11331145.

Boerner, M., \& Krüger, O. (2009). Aggression and fitness differences between plumage morphs in the common buzzard (Buteo buteo). Behavioral Ecology, 20, 180-185.

Carter, A. J., Goldizen, A. W., \& Tromp, S. A. (2010). Agamas exhibit behavioral syndromes: bolder males bask and feed more but may suffer higher predation. Behavioral Ecology, 21, 655-661.

Carter, A. J., Marshall, H. H., Heinsohn, R., \& Cowlishaw, G. (2012). How not to measure boldness: novel object and antipredator responses are not the same in wild baboons. Animal Behaviour, 84, 603-609.

Conover, M. R. (1994). Stimuli eliciting distress calls in adult passerines and response of predators and birds to their broadcast. Behaviour, 131, 19-37.

Conover, W. J., \& Iman, R. L. (1981). Rank transformations as a bridge between parametric and nonparametric statistics. American Statistician, 35, 124-129.

Couchoux, C., \& Cresswell, W. (2012). Personality constraints versus flexible antipredation behaviors: how important is boldness in risk management of redshanks (Tringa totanus) foraging in a natural system? Behavioral Ecology, 23, 290-301.

Cresswell, W., Quinn, J. L., Whittingham, M. J., \& Butler, S. (2003). Good foragers can also be good at detecting predators. Proceedings of the Royal Society B: Biological Sciences, 270, 1069-1076.

Da Silva, A., Brink, V., Emaresi, G., Luzio, E., Bize, P., Dreiss, A. N., et al. (2013). Melanin-based colour polymorphism signals aggressive personality in nest and territory defence in the tawny owl (Strix aluco). Behavioral Ecology and Sociobiology, 67, 1041-1052.

Dammhahn, M., \& Almeling, L. (2012). Is risk taking during foraging a personality trait? A field test for cross-context consistency in boldness. Animal Behaviour, 84, 1131-1139. 
David, M., Auclair, Y., \& Cézilly, F. (2011). Personality predicts social dominance in female zebra finches, Taeniopygia guttata, in a feeding context. Animal Behaviour, 81, 219-224.

Ducrest, A. L., Keller, L., \& Roulin, A. (2008). Pleiotropy in the melanocortin system, coloration and behavioural syndromes. Trends in Ecology \& Evolution, 23, 502-510.

Ekman, J. B. (1987). Exposure and time use in willow tit flocks: the cost of subordination. Animal Behaviour, 35, 445-452.

Godin, J. G., \& Dugatkin, L. A. (1996). Female mating preference for bold males in the guppy, Poecilia reticulata. Proceedings of the National Academy of Sciences of the United States of America, 93, 10262-10267.

Guillette, L. M., \& Sturdy, C. B. (2011). Individual differences and repeatability in vocal production: stress-induced calling exposes a songbird's personality. Naturwissenschaften, 98 , 977-981.

Hart, A., \& Lendrem, D. W. (1984). Vigilance and scanning patterns in birds. Animal Behaviour, $32,1216-1224$.

Jones, K., \& Godin, J. G. 2010. Are fast explorers slow reactors? Linking personality type and anti-predator behaviour. Proceedings of the Royal Society B: Biological Sciences, 277, 625-632.

Koivula, K., Lahti, K., Rytkönen, S., \& Orell, M. (1994). Do subordinates expose themselves to predation? Field experiments on feeding site selection by willow tits. Journal of Avian Biology, $25,178-183$.

Laiolo, P., Tella, J. L., Carrete, M., Serrano, D., \& López, G. (2004). Distress calls may honestly signal bird quality to predators. Proceedings of the Royal Society B: Biological Sciences, 271(Suppl.), S513-S515.

Lima, S. L., \& Dill, L. M. (1990). Behavioral decisions made under the risk of predation: a review and prospectus. Canadian Journal of Zoology, 68, 619-640.

Mateos-González, F., \& Senar, J. C. (2012). Melanin-based trait predicts individual exploratory behaviour in siskins, Carduelis spinus. Animal Behaviour, 83, 229-232.

Pascual, J., \& Senar, J. C. (2013). Differential effects of predation risk and competition over vigilance variables and feeding success in Eurasian siskins (Carduelis spinus). Behaviour, 150, 1665-1687.

Pascual, J., Senar, J. C., \& Domènech, J. (2014). Plumage brightness, vigilance, escape potential, and predation risk in male and female Eurasian siskins (Carduelis spinus). Auk:Ornithological advances, 131, 61-72.

Quesada, J., \& Senar, J. C. (2007). The role of melanin- and carotenoid-based plumage coloration in nest defence in the great tit. Ethology, 113, 640-647. 
Quinn, J. L., Cole, E. F., Bates, J., Payne, R. W., \& Cresswell, W. (2011). Personality predicts individual responsiveness to the risks of starvation and predation. Proceedings of the Royal Society B: Biological Sciences, 279, 1919-1926.

Quinn, J. L., \& Cresswell, W. (2005). Personality, anti-predation behaviour and behavioural plasticity in the chaffinch Fringilla coelebs. Behaviour, 142, 1377-1402.

Réale, D., Reader, S. M., Sol, D., McDougall, P. T., \& Dingemanse, N. J. (2007). Integrating animal temperament within ecology and evolution. Biological Reviews, 82, 291-318.

Reyer, H. U., Fischer, W., \& Steck, P. (1998). Sex-specific nest defense in house sparrows (Passer domesticus) varies with badge size of males. Behavioral Ecology and Sociobiology, 42, 93-99.

Senar, J. C. (1988). Trapping finches with the Yunick platform trap: the residency bias. Journal of Field Ornithology, 59, 381-384.

Senar, J. C. (2006). Color displays as intrasexual signals of aggression and dominance. In G. E. Hill \& K. J. McGraw (Eds.), Bird coloration: Function and Evolution (Vol. 2, pp. 87-136). Cambridge, MA: Harvard University Press.

Senar, J. C., Burton, P. J. K., \& Metcalfe, N. B. (1992). Variation in the nomadic tendency of a wintering finch Carduelis spinus and its relationship with body condition. Ornis Scandinavica, 23, 63-72.

Senar, J. C., \& Camerino, M. (1998). Status signalling and the ability to recognize dominants: an experiment with siskins (Carduelis spinus). Proceedings of the Royal Society B: Biological Sciences, 265, 1515-1520.

Senar, J. C., Camerino, M., Copete, J. L., \& Metcalfe, N. B. (1993). Variation in black bib of the Eurasian siskin (Carduelis spinus) and its role as a reliable badge of dominance. Auk, 110, 924927.

Senar, J. C., \& Domènech, J. (2011). Sex-specific aggression and sex ratio in wintering finch flocks: serins and siskins differ. Acta Ethologica, 14, 7-11.

Senar, J. C., Polo, V., Uribe, F., \& Camerino, M. (2000). Status signalling, metabolic rate and body mass in the siskin: the cost of being a subordinate. Animal Behaviour, 59, 103-110.

Sih, A., Bell, A., \& Johnson, J. C. (2004). Behavioral syndromes: an ecological and evolutionary overview. Trends in Ecology \& Evolution, 19, 372-378.

Sih, A., Kats, L. B., \& Maurer, E. F. (2003). Behavioural correlations across situations and the evolution of antipredator behaviour in a sunfish-salamander system. Animal Behaviour, 65, 29-44.

Smith, B. R., \& Blumstein, D. T. (2007). Fitness consequences of personality: a meta-analysis. Behavioral Ecology, 19, 448-455. 
Sternalski, A., \& Bretagnolle, V. (2010). Experimental evidence of specialised phenotypic roles in a mobbing raptor. Behavioral Ecology and Sociobiology, 64, 1351-1361.

van den Brink, V., Dolivo, V., Falourd, X., Dreiss, A. N., \& Roulin, A. (2012). Melanic colordependent antipredator behavior strategies in barn owl nestlings. Behavioral Ecology, 23, 473480.

van Oers, K., Drent, P. J., de Goede, P., \& Van Noordwijk, A. J. (2004). Realized heritability and repeatability of risk-taking behaviour in relation to avian personalities. Proceedings of the Royal Society B: Biological Sciences, 271, 65-73.

Whittingham, M. J., Butler, S. J., Quinn, J. L., \& Cresswell, W. (2004). The effect of limited visibility on vigilance behaviour and speed of predator detection: implications for the conservation of granivorous passerines. Oikos, 106, 377-385.

Wolf, M., van Doorn, G. S., Leimar, O., \& Weissing, F. J. (2007). Life-history trade-offs favour the evolution of animal personalities. Nature, 447, 581-584. 


\section{Table 1}

Comparison of different vigilance and foraging variables between pairs of siskins differing in bib size and foraging at two feeders differing in predation risk

\begin{tabular}{|c|c|c|c|c|c|c|}
\hline & & \multicolumn{2}{|l|}{ Mean \pm SE } & \multirow[t]{2}{*}{$F$} & \multirow[t]{2}{*}{$d f$} & \multirow[t]{2}{*}{$P$} \\
\hline & & LPF/large bib & HPF/small bib & & & \\
\hline \multirow{4}{*}{$\begin{array}{l}\text { Reciprocal of } \\
\text { interscan } \\
\text { duration (s) }\end{array}$} & (Intercept) & & & 660.4 & 1,38 & $<0.0001$ \\
\hline & Feeder & $0.88 \pm 0.05$ & $0.65 \pm 0.07$ & 12.1 & 1,38 & 0.001 \\
\hline & $\mathrm{Bib}$ & $0.68 \pm 0.04$ & $0.85 \pm 0.07$ & 7.4 & 1,38 & 0.010 \\
\hline & Bib*feeder & & & 0.6 & 1,38 & 0.462 \\
\hline \multirow{4}{*}{$\begin{array}{l}\text { Scan rate } \\
\text { (scans/s) }\end{array}$} & (Intercept) & & & 981.9 & 1,38 & $<0.0001$ \\
\hline & Feeder & $0.55 \pm 0.02$ & $0.69 \pm 0.03$ & 12.1 & 1,38 & 0.001 \\
\hline & Bib & $0.65 \pm 0.02$ & $0.59 \pm 0.03$ & 4.2 & 1,38 & 0.047 \\
\hline & Bib*feeder & & & 0.0 & 1,38 & 0.847 \\
\hline \multirow{4}{*}{$\begin{array}{l}\text { Cube of \% time } \\
\text { scanning }\end{array}$} & (Intercept) & & & 198.8 & 1,38 & $<0.0001$ \\
\hline & Feeder & $0.55 \pm 0.02$ & $0.58 \pm 0.03$ & 0.3 & 1,38 & 0.571 \\
\hline & Bib & $0.59 \pm 0.02$ & $0.54 \pm 0.03$ & 1.6 & 1,38 & 0.217 \\
\hline & Bib*feeder & & & 0.1 & 1,38 & 0.769 \\
\hline \multirow{4}{*}{$\begin{array}{l}\text { Logarithm of } \\
\text { pecking rate } \\
\text { (pecks/s) }\end{array}$} & (Intercept) & & & 10.6 & 1,38 & 0.002 \\
\hline & Feeder & $0.90 \pm 0.06$ & $0.93 \pm 0.08$ & 0.2 & 1,38 & 0.659 \\
\hline & Bib & $0.86 \pm 0.05$ & $0.97 \pm 0.08$ & 1.0 & 1,38 & 0.325 \\
\hline & Bib*feeder & & & 0.0 & 1,38 & 0.984 \\
\hline \multirow{3}{*}{$\begin{array}{l}\text { Ranked } \\
\text { survival scores } \\
\text { of time on } \\
\text { feeder }\end{array}$} & (Intercept) & & & 266.8 & 1,40 & $<0.0001$ \\
\hline & Feeder & $12.8 \pm 7.4$ & $-11.7 \pm 7.8$ & 7.3 & 1,40 & 0.010 \\
\hline & Bib & $9.0 \pm 6.8$ & $-7.9 \pm 7.9$ & 2.1 & 1,40 & 0.154 \\
\hline \multirow{3}{*}{$\begin{array}{l}\text { Ranked \% time } \\
\text { spent in } \\
\text { aggression }\end{array}$} & (Intercept) & & & 169.8 & 1,40 & $<0.0001$ \\
\hline & Feeder & $3.21 \pm 0.70$ & $2.25 \pm 0.73$ & 0.9 & 1,40 & 0.340 \\
\hline & Bib & $2.77 \pm 0.52$ & $2.69 \pm 0.58$ & 0.9 & 1,40 & 0.343 \\
\hline
\end{tabular}

LPF: low predation risk feeder; HPF: high predation risk feeder. Results of repeated measures ANOVAs are given for the comparison between feeders, between pairs of siskins and for the interaction feeder*bib size. Most variables were transformed to allow use of parametric statistics, but means $\pm S E$ are given for the untransformed variables. The first four variables were estimated from the undisturbed subsample ( $N=26$ pairs for LPF, $N=14$ pairs for HPF) and the last two variables were estimated from the random subsample ( $N=22$ pairs for LPF, $N$ $=20$ pairs for HPF). Interactions of ranked data could not be tested because of limitations of statistical procedures. 
Figure 1. Mean $\pm S E(a)$ interscan duration and (b) scan rate of paired transient male siskins differing in black bib size. $\mathrm{N}=40$ pairs. $\mathrm{P}$ level was calculated from a repeated measures ANOVA with the transformed variables.
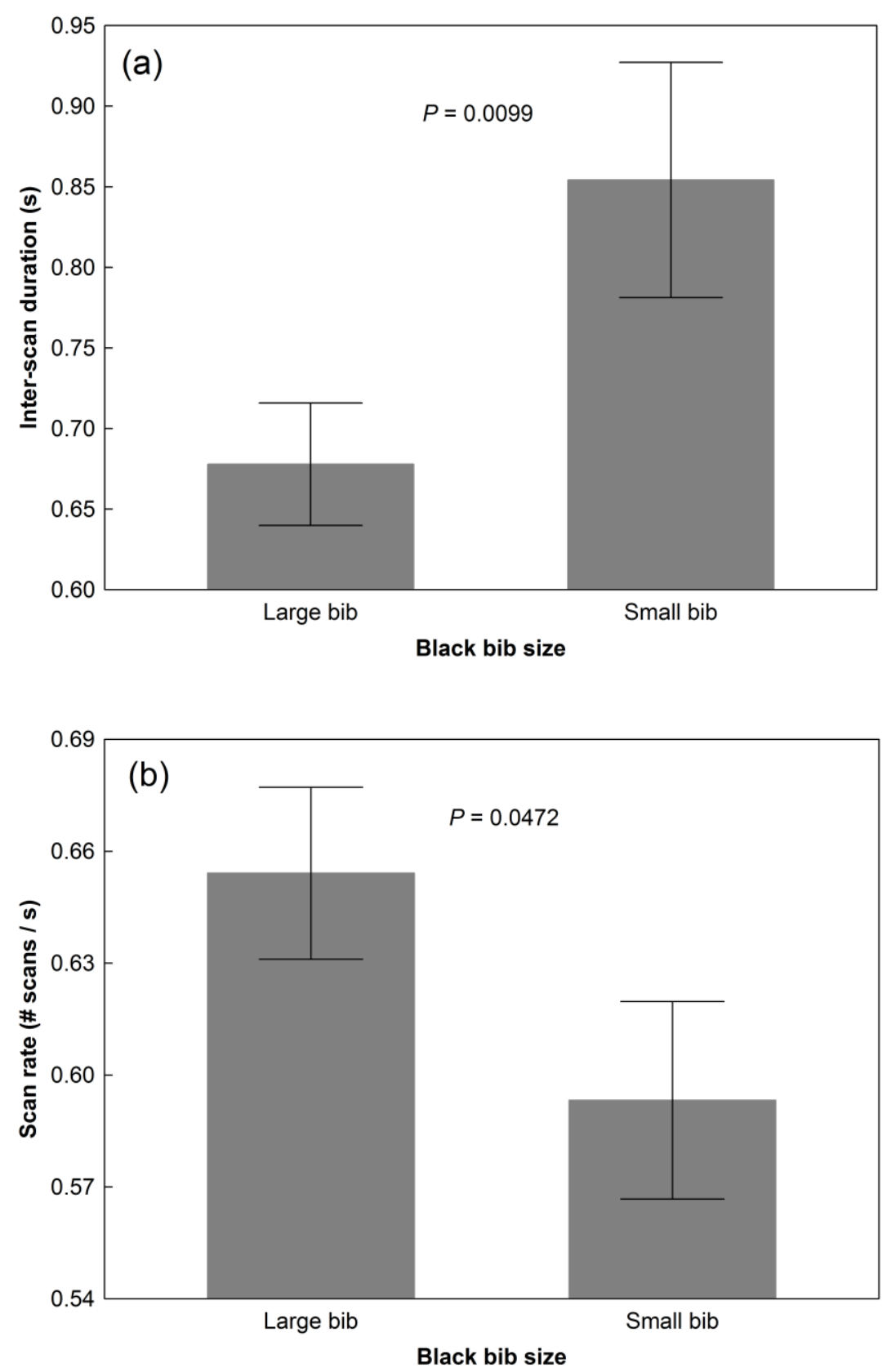
Figure 2. Mean $\pm S E$ black bib area (in $\mathrm{mm} 2$ ) of male siskins that uttered $(\mathrm{N}=57$ ) and did not utter ( $N=667$ ) distress calls when handled by bird ringers. Data from the winters of 19901991 and 1996-1997 were pooled ( $N=724$ birds). $P$ level was calculated from a MannWhitney $U$ test.

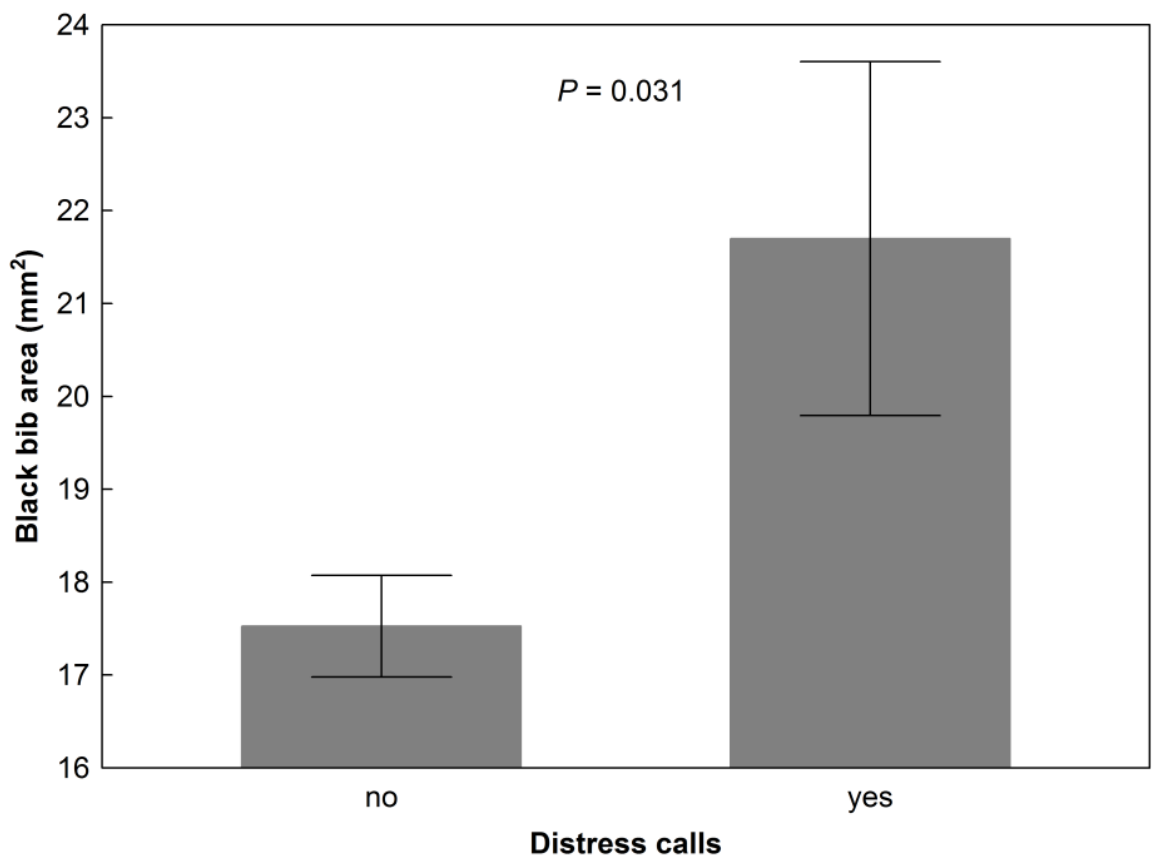

